\title{
Two Cases of Oligometastatic Basal Cell Carcinoma: A Comparison of Pathology Characteristics and Discussion of Systemic and Radiotherapeutic Management Strategies
}

\author{
Alexandra Waters ${ }^{1}$, Laura Masucci ${ }^{2}$, Annie Belisle ${ }^{3}$, Louise Lambert ${ }^{1}$ \\ 1. Department of Radiation Oncology, Centre hospitalier de l'Université de Montréal (CHUM) 2. Department of \\ Radiation Oncology, Centre hospitalier de l'Université de Montréal (CHUM), Montreal, CAN 3. Pathology, Centre
} hospitalier de l'Université de Montréal (CHUM)

$\square$ Corresponding author: Alexandra Waters, alexandra.waters@hotmail.com

Disclosures can be found in Additional Information at the end of the article

\begin{abstract}
Metastatic basal cell carcinoma (BCC) cases are rare and clinically challenging. We are reporting two such cases, which were seen at a short interval from one another, in order to outline and compare case features indicative of an aggressive BCC. Furthermore, we wish to discuss the role and delivery of radiation therapy in the treatment of this disease in the metastatic setting, including the use of stereotactic ablative radiotherapy. Finally, we address the use of vismodegib as it was made in these cases.
\end{abstract}

Received 08/03/2014

Review began 08/03/2014

Review ended 10/15/2014

Published 10/31/2014

(c) Copyright 2014

Waters et al. This is an open access article distributed under the terms of the Creative Commons Attribution License CC-BY 3.0 which permits unrestricted use, distribution, and reproduction in any medium, provided the original author and source are credited.
Categories: Dermatology, Radiation Oncology, Oncology

Keywords: basocellular, basal cell, carcinoma, oligometastatic, metastatic, hedgehog, stereotactic ablative radiotherapy (sabr), radiation oncology, vismodegib, basosquamous

\section{Introduction}

Basal cell carcinoma (BCC) is the most common form of cancer in Canada, representing, together with squamous cell carcinoma of the skin, an estimated 81,700 new cases in 2013 [1]. However, it is seldom metastatic, with fewer than 300 cases worldwide reported in the literature between 1981 and 2011. In metastatic patients, one-third have pulmonary disease and one-fifth have bone metastases [2]. Due to this rarity, the literature on the treatment of this disease has consisted mostly of case reports before the publication of the vismodegib trial. In this article, we are reporting two rare cases of patients who presented with oligometastatic BCC. The choices of local and systemic treatments are presented and discussed. Informed patient consent was obtained for both patients. All identifying information has been suppressed in order to maintain patient confidentiality.

\section{Case Presentation}

\section{Case one}

A 31-year-old patient presented with a cutaneous lesion extending from the left retroauricular region to the base of his scalp, as well as the posterior ear lobe. A biopsy revealed the lesion to be a BCC, and it was resected in February of 2002, two to three years after the patient first noticed it. At this point, it was 20 to 25 centimeters wide. The lesion was infiltrative and nodular, and surgical margins were positive.

A first relapse in the summer of the same year led to a second resection and skin graft. The operative margins were free of disease. In the years that followed, he underwent several additional surgeries due to relapses, with resections extending towards his left ear. In 2006, after a surgery that left behind deep positive margins, he was referred to the radiation oncology department where it was recommended that he should undergo adjuvant radiotherapy. The pathology report at this time described an extensive infiltration of the tissues by the BCC. Due to his young age, however, the surgery team decided with the patient to avoid radiotherapy and surgically remove the residual disease. Five additional resections took place between 2008 and 2011, reaching the left side of the face, the mastoid process, and the inner ear canal, as well as the parotid with damage to the facial nerve. A change in the subtype of BCC was noted in 2008, going from a nodular type, to an infiltrative and basosquamous one. This last feature remains present in most of the subsequent specimens.

\section{How to cite this article}

Waters A, Masucci L, Belisle A, et al. (October 31, 2014) Two Cases of Oligometastatic Basal Cell Carcinoma: A Comparison of Pathology Characteristics and Discussion of Systemic and Radiotherapeutic Management Strategies. Cureus 6(10): e222. DOI 10.7759/cureus.222 


\section{Cureus}

\begin{tabular}{|c|c|c|}
\hline Date & Event & Pathology \\
\hline $\begin{array}{l}\text { February } \\
2002\end{array}$ & Prımary resected $(20-25 \mathrm{~cm})$ & $\begin{array}{l}\text { Infiltrative BCC, nodular features. } \\
\text { Positive margins. }\end{array}$ \\
\hline $\begin{array}{l}2002- \\
2006\end{array}$ & Resection of relapses & $\begin{array}{l}\text { Same as above, with extensive } \\
\text { infiltration of tissues }\end{array}$ \\
\hline 2006 & Referred to radiation oncology, choice made not to give RT & Deep positive margins \\
\hline $\begin{array}{l}2008- \\
2011\end{array}$ & Five further resections & $\begin{array}{l}\text { Change from nodular subtype to } \\
\text { basosquamous }\end{array}$ \\
\hline $\begin{array}{l}\text { October } \\
2011\end{array}$ & $\begin{array}{l}\text { Adjuvant RT delivered: } 60 \mathrm{~Gy} / 30 \text { fractions via tomotherapy Pulmonary metastasis } \\
\text { discovered Bone metastases discovered }\end{array}$ & $\begin{array}{l}\text { Spine and lung lesions confirmed to } \\
\text { be BCC metastases }\end{array}$ \\
\hline $\begin{array}{l}\text { December } \\
2011\end{array}$ & SABR to lumbar (L5) metastasıs: $24 \mathrm{~Gy} / 2$ tractions & \\
\hline $\begin{array}{l}\text { January } \\
2012\end{array}$ & Vismodegib initiated & \\
\hline July 2013 & Pulmonary nodule progression -SABR $60 \mathrm{~Gy} / 5$ fractions -Vismodegib on hold 3 weeks & \\
\hline $\begin{array}{l}\text { November } \\
2013\end{array}$ & $\begin{array}{l}\text { L5 relapse -Surgical excision with fusion L4-S1 -Adjuvant SABR to L5: 30Gy/5 } \\
\text { fractions -Vismodegib ceased, cisplatin/5-FU initiated }\end{array}$ & \\
\hline April 2014 & PET-scan: no hypermetabolic activity at L5, nor at site of treated pulmonary lesion & \\
\hline
\end{tabular}

TABLE 1: Patient One: Summary of Events and Pathological Characteristics

In 2011, the interdisciplinary oncology team decided to go forth with an adjuvant treatment of radiation as the margins were persistently positive. He received $60 \mathrm{~Gy}$ in 30 fractions to the left parotid and neck region, delivered by tomotherapy. Treatments took place between October and November of 2011 and were welltolerated by the patient. However, prior to the treatments, a scan of the neck revealed pulmonary lesions at the upper lobe of the right lung. A PET scan was performed, which confirmed the presence of three hypermetabolic lesions: one in the right lung and two bone metastases at the L5 vertebral body and the right ilium. Biopsies were carried out in the spine and the lung, and immunohistochemical analysis confirmed that these were in fact metastases of a BCC.

The lumbar metastasis was addressed by stereotactic ablative radiotherapy (SABR) of $24 \mathrm{~Gy}$ in two fractions in December of 2011. The patient was also included in the STEVIE research protocol, a single-arm, openlabel, international study, in which he was treated with vismodegib, an inhibitor of the Hedgehog signaling pathway (protocol \#MO25616) [3]. He received his first dose in January 2012. The regimen consists of a once-daily oral dose of $150 \mathrm{mg}$. This patient presented some drug-induced toxicities, but overall, the treatments were well-tolerated. These consisted of alopecia, dysgeusia, fatigue, muscle cramps, and dyspnea, though all were reported as mild in their severity. The pulmonary metastasis was not treated at this time, as it was asymptomatic and would serve to evaluate tumor response to vismodegib.

Vismodegib therapy was maintained, and follow-up scans demonstrated a stability of all lesions until that of July 2013, which showed that the vertebral lesion was stable, but there was progression of the pulmonary nodule. This right upper lobe lesion was treated by SABR and $60 \mathrm{~Gy}$ were delivered in five fractions. At this time, vismodegib treatments were put on hold for three weeks. No radiation-induced toxicity was reported. A thoracic scan in November 2013 showed complete regression of this nodule.

Unfortunately, in November of the same year, he presented neurological symptoms that led to the discovery of a relapse at the L5 vertebral body. He underwent surgical excision of the tumour and instrumental fusion of vertebras L4 to S1. This was followed by a second stereotaxic irradiation of L5: 30 Gy was delivered in five fractions, with $80 \%$ of the mass intentionally receiving $35.6 \mathrm{~Gy}$ and $60 \%$ receiving $38 \mathrm{~Gy}$ in order to maintain adequate doses administered to the surrounding organs at risk (Figure 1). This treatment ended December 13, 2013, with no early or late adverse effects noted. At this time, vismodegib was ceased and a treatment of cisplatin and 5-FU was initiated. 


\section{Cureus}
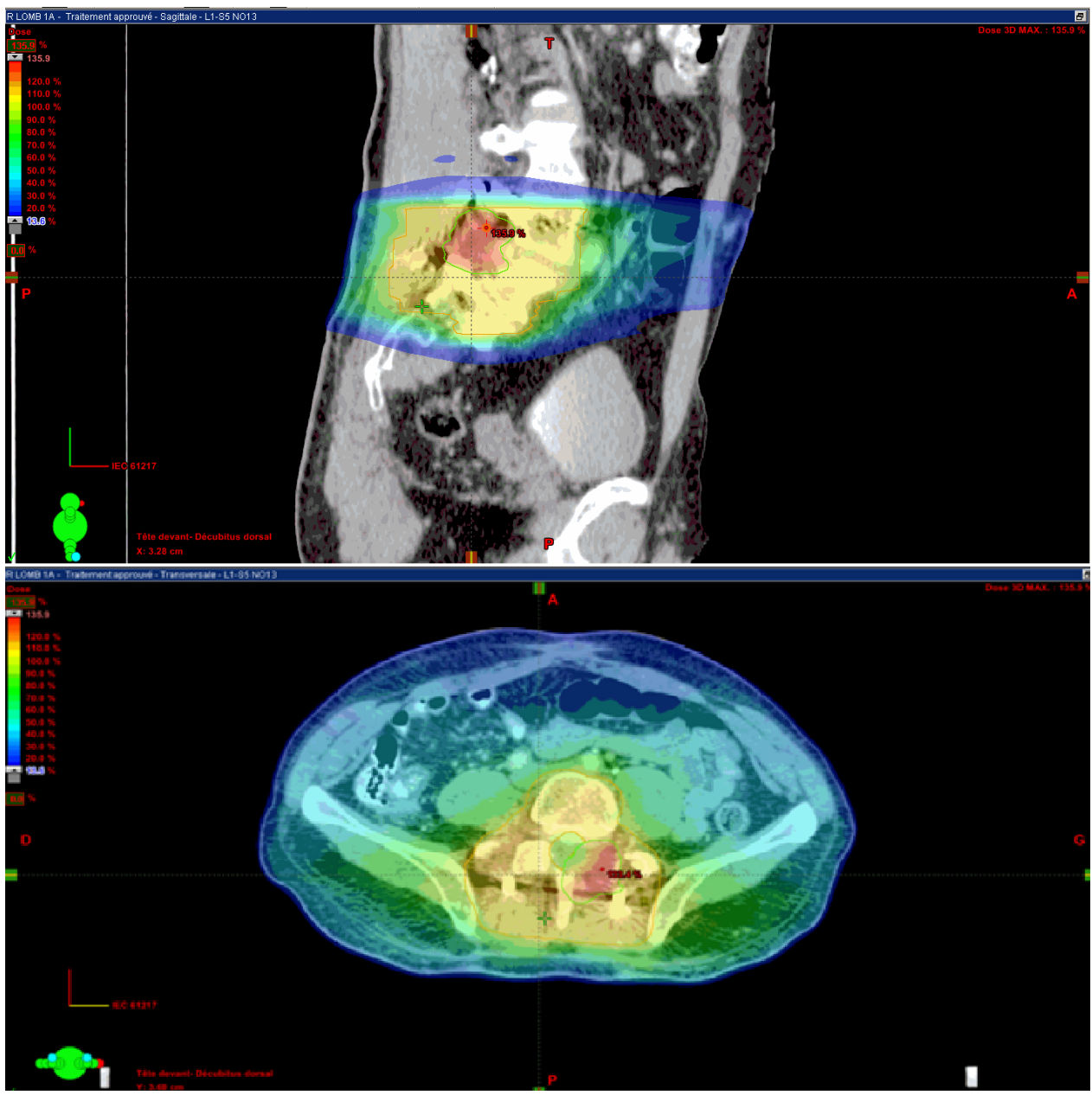

FIGURE 1: Stereotaxic reirradiation of L5: $30 \mathrm{~Gy}$ in five fractions.

This technique allowed for dose escalation to the residual mass.

A PET-scan obtained in April 2014 showed no evidence of hypermetabolic activity at L5, nor at the site of the treated pulmonary lesion. No relapse has been noted at the site of primary disease.

\section{Case two}

A 33-year-old patient presented with what she described as a skin tag above her right breast. It was first discovered in 2001 and was resected the same year. Unfortunately, as this was done in a private cabinet, the specimen and pathology report were irretrievable. The skin was clear until 2006, when a small lesion reappeared. It grew progressively larger until she sought a medical opinion in April of 2013. It was biopsied and revealed to be a BCC with morpheaform and infiltrative features (Figure 2). At that time, it measured close to $13 \mathrm{~cm}$ in diameter. It was resected one month later. Upon pathological analysis, it was found to invade the hypodermis and the deep margins were positive. An unusual pathological feature in this case was the presence of lymphovascular invasion. 


\section{Cureus}

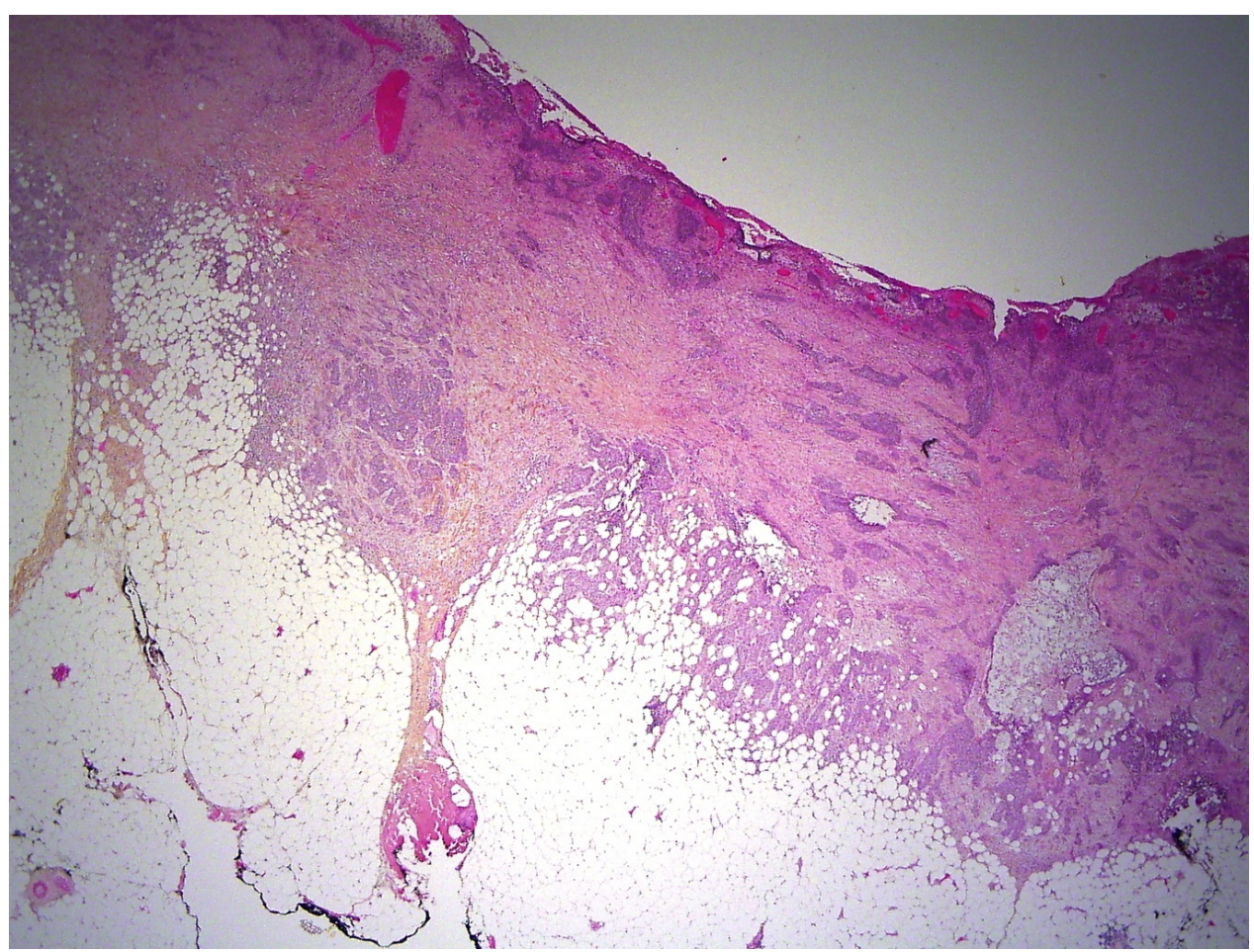

FIGURE 2: Cutaneous specimen showing basal cell carcinoma with lymphovascular invasion.

Second patient, resection $2013,2 x$

In July of the same year, she sought consultation for bilateral leg paresthesias, and a MRI revealed a single lesion located at T3, which had caused the collapse of the vertebral body, resulting in cord compression. The neurosurgical team performed a corpectomy of the lesion. Upon examination of the surgical specimen, the bony infiltration was found to be a metastasis of the basal cell carcinoma displaying nodular features. The paresthesias resolved. She was meant to be evaluated by the radiation oncology team for adjuvant radiotherapy, but failed to meet her first three appointments. She was finally seen three months after her surgery, at which time she was experiencing a relapse of her neurological symptoms. She was prescribed radiation treatments of $20 \mathrm{~Gy}$ in five fractions, delivered by a standard posterior field from T1 to T5. However, the patient did not attend her last session, thus receiving a total of $16 \mathrm{~Gy}$ in four fractions. There has been no relapse of neurological symptoms since the treatments in November 2013, and a MRI of the spine in April 2014 showed no evidence of relapse.

A complete work-up was done in July 2013. A chest scan revealed bilateral micronodules, as well as a $9 \mathrm{~mm}$ nodule in the lingula. A clinically evident supraclavicular adenopathy was measured at $12 \mathrm{~mm}$. These findings were hypermetabolic on PET-scan. Consequently, the patient initiated vismodegib treatments, which by this time were available outside of a research protocol. A month later, her supraclavicular mass was barely palpable, and another month later, it had completely regressed. Vismodegib treatments were interrupted for a period of one month in March 2014 because the patient failed to undergo the pregnancy test required; she has subsequently been compliant. A thoracic scan was done in July 2014, which demonstrated that the pulmonary nodule situated in the lingula was smaller: $11 \times 7 \mathrm{~mm}$ versus $11 \mathrm{x} 10 \mathrm{~cm}$ in December 2013.

\section{Discussion}

Adjuvant radiation therapy is widely recommended to reduce the local recurrence rate in high-risk patients [4-5]. High-risk factors include a lesion larger than $2 \mathrm{~cm}$, location in the mid face or ear, duration without treatment, a history of previous irradiation [6], as well as irregular borders [7]. Additionally, the following are considered high-risk pathologic subtypes: morpheaform, basosquamous, sclerosing, mixed infiltrative, and micronodular [5-6]. Immunosuppression has been described as a risk factor for metastasis in squamous cell carcinoma [8], and, though there is no direct evidence to support it, it is thought to have the same significance in BCC. Of note, a retrospective analysis of 7,732 head and neck BCC treated at an academic center, published by Mulvaney, et al., demonstrated that BCC of the ear seemed to present as larger lesions, required more Mohs layers, and produced a larger final defect than non-ear lesions [9]. 
Should our first patient have received adjuvant radiotherapy in 2006? His was a large, relapsing lesion with extensive tissue infiltration upon pathological examination. Studies suggest a local control rate of $2 \%$ to $6 \%$ in recurrent BCC treated with Moh's surgery [10-11] to negative margins, which does not support the necessity of adjuvant treatment based on recurrence only. Because of his age, the risk of secondary cancer, the surgical challenge to operate an irradiated site should he relapse, and the cosmetic results due to accelerated skin aging had to be taken into account. He did undergo adjuvant radiotherapy in November 2011 in the context of persistently positive margins and has since presented no evidence of local relapse. Of note, there is no data pertaining to the relationship between local control and the occurrence of distant metastases, such that one cannot conclude whether the course of this patient's disease would have been altered by earlier irradiation.

Interestingly, both patients had an aggressive form of BCC, displaying either morpheaform or basosquamous features. In the case of the first patient, it appeared in the primary lesion several years after the initial resection and was present in the pulmonary metastasis. Although basosquamous carcinoma represents less than $3 \%$ of non-melanoma skin cancers, several retrospective analyses have outlined its more aggressive clinical course and consider it to have a distinctly worse prognosis than other forms of BCC, with a metastatic rate of at least 5\% [12]. The appearance of this feature must therefore be seen a sign of aggressive transformation. In the second case, morpheaform features were present at diagnosis. Lesions of this subtype have previously been reported as having deeper invasion, higher rates of incomplete excision, and more frequent recurrences [13]. Data pertaining to the metastatic rate of this subtype are, however, too scarce to determine whether it is more likely to spread distantly. Perhaps this locally aggressive behavior and poorer local control allow more time for the development of metastases, or it may be inherently more aggressive and likely to metastasize. Another unusual pathological feature in the second patient's specimens was the presence of lymphovascular invasion, which is uncommon in BCC. Though, to our knowledge, there is no literature on the prognostic value of this feature, it should most likely be considered unfavorable.

As there is only anecdotal data pertaining to doses delivered to metastases from BCC, radiation regimens were extrapolated from other pathologies. In the case of the first patient, the dose delivered to the pulmonary lesion represents the curative dose given with SABR to non-operable, early-stage, non-small cell lung cancer (NSCLC) tumors in our center. As for the spinal lesion, we chose to treat with SABR rather than a standard posterior field, as this allows higher accuracy and steep dose fall-off, and its efficacy in local control and pain relief is being increasingly demonstrated [14]. However, there are insufficient reported cases of metastatic BCC treated with SABR to conclude that this is more efficient than conventional palliative radiotherapy, which is to be weighed against the increased cost and complexity of the delivery of such a treatment. Though the median survival after diagnosis of metastases is 10 months, the survival range goes up as high as 108 months [2]. As oligometastatic BCC disease evolves slowly over several years, we believe that providing high doses, while minimizing toxicities and allowing the possibility of safe retreatment, is of particular importance. SABR should be considered in such cases, and further investigation is warranted. The same approach would have been attempted for the second patient's spinal disease, but her poor compliance led us to choose a standard approach, as this is what was available on the day she came for her consultation. Another question is whether the initial spinal dose given to the first patient, $24 \mathrm{~Gy}$ in two fractions, was sufficient, as it did not in this case provide durable tumor control. Is metastatic BCC disease more resistant, and what should the minimal dose be? If we compare to a well-known radioresistant tumor type, the local control rate of spinal metastases from renal cell carcinoma treated by SABR to similar doses is $80 \%$ one year after treatment [15].

A promising avenue in the treatment of metastatic BCC is targeted systemic therapy. In a Phase II study of vismodegib, the first Hedgehog signaling pathway targeting agent to gain U.S. Food and Drug Administration (FDA) approval, 33 metastatic patients were enrolled. Ten of these presented a favorable radiologic response to treatment [16]. Both our patients responded clinically and radiologically. However, the first patient progressed approximately 18 months after initiation of this therapy. A resistance phenomenon following response to vismodegib has been observed [17]. This indicates the existence of a mechanism of secondary resistance, which has yet to be completely elucidated. This warrants further research for alternate molecular targets and the development of targeted therapies that may be used after development of resistance to a Hedgehog inhibitor, or concomitantly with it, to prevent this phenomenon.

As the use of this drug becomes more widespread among metastatic and advanced non-operable BCC, perhaps we can ask the question of whether this drug could also act as a radiosensitizer and be used in concomitance with radiotherapy in order to potentiate tumoricidal activity. Though no human trial has taken place to date, a study has evaluated the combined effects of a targeted Hedgehog inhibitor and radiation on mouse models. They used NSCLC human xenografts and murine-inducible transgenic models, and the Hedgehog inhibitor enhanced radiation efficacy and delayed tumor growth in both [18]. The safety and toxicity profile of such a combination has yet to be documented.

\section{Conclusions}


Though few BCC patients develop metastases, this disease can prove to be aggressive and challenging to manage. It is crucial to identify disease characteristics that allow us single out these high-risk patients early in their disease progression. In locally advanced and metastatic cases, new systemic therapeutic options are under investigation and are being incorporated into the management strategy. As early data indicates the emergence of secondary resistance to vismodegib, further research into alternate targeted therapies, as well as possible concomitant regimens, is needed. In managing oligometastatic BCC patients, one should always keep in mind the slow progression of the disease and choose treatment options, such as SABR, which may favor better long-term control.

\section{Additional Information \\ Disclosures}

Human subjects: Consent was obtained by all participants in this study. Patient One was included in the STEVIE research protocol issued approval protocol number MO25616. Conflicts of interest: In compliance with the ICMJE uniform disclosure form, all authors declare the following: Payment/services info: All authors have declared that no financial support was received from any organization for the submitted work. Financial relationships: All authors have declared that they have no financial relationships at present or within the previous three years with any organizations that might have an interest in the submitted work. Other relationships: All authors have declared that there are no other relationships or activities that could appear to have influenced the submitted work.

\section{References}

1. Canadian Cancer Society's Steering Committee on Cancer Statistics: Canadian Cancer Statistics 2012. Canadian Cancer Society. 2012, 1-67.

http://www.cancer.ca/ /media/cancer.ca/CW/cancer\%20information/cancer\%20101/Canadian\%20cancer\%20statistic: C....

2. Wysong A, Aasi SZ, Tang JY: Update on metastatic basal cell carcinoma: A summary of published cases from 1981 through 2011. JAMA Dermatol. 2013, 149:615-6. 10.1001/jamadermatol.2013.3064

3. Axelson M, Liu K, Jiang X, He K, Wang J, Zhao H, Kufrin D, Palmby T, Dong Z, Russell AM, Miksinski S, Keegan P, Pazdur R: U.S. Food and Drug Administration approval: Vismodegib for recurrent, locally advanced, or metastatic basal cell carcinoma. Clin Cancer Res. 2013, 19:2289-93. 10.1158/1078-0432.CCR12-1956

4. Mendenhall WM, Amdur RJ, Hinerman RW, Cognetta AB, Mendenhall NP: Radiotherapy for cutaneous squamous and basal cell carcinomas of the head and neck. Laryngoscope. 2009, 119:1994-9. 10.1002/lary.20608

5. National Comprehensive Cancer Network: Basal and Squamous Cell Skin Cancers. 2014, 2.2014:Accessed: October 1, 2014: http://www.nccn.org/professionals/physician_gls/pdf/nmsc.pdf.

6. Randle HW: Basal cell carcinoma. Identification and treatment of the high-risk patient . Dermatol Surg. 1996, 22:255-61.

7. Rowe DE, Carroll RJ, Day CL Jr: Long-term recurrence rates in previously untreated (primary) basal cell carcinoma: implications for patient follow-up. J Dermatol Surg Oncol. 1989, 15:315-28.

8. Brantsch KD, Meisner C, Schönfisch B, Trilling B, Wehner-Caroli J, Röcken M, Breuninger H: Analysis of risk factors determining prognosis of cutaneous squamous-cell carcinoma: A prospective study. Lancet Oncol. 2008, 9:713-20. 10.1016/S1470-2045(08)70178-5

9. Mulvaney PM, Higgins HW 2nd, Dufresne RG Jr, Cruz AP, Lee KC: Basal cell carcinomas of the ear are more aggressive than on other head and neck locations. J Am Acad Dermatol. 2014, 70:924-6. 10.1016/j.jaad.2013.12.021

10. Rowe DE, Carroll RJ, Day CL Jr: Mohs surgery is the treatment of choice for recurrent (previously treated) basal cell carcinoma. J Dermatol Surg Oncol. 1989, 15:424-31.

11. Mosterd K, Krekels GA, Nieman FH, Ostertag JU, Essers BA, Dirksen CD, Steijlen PM, Vermeulen A, Neumann H, Kelleners-Smeets NW: Surgical excision versus Mohs' micrographic surgery for primary and recurrent basal-cell carcinoma of the face: a prospective randomised controlled trial with 5-years' follow-up. Lancet Oncol. 2008, 9:1149-56. 10.1016/S1470-2045(08)70260-2

12. Garcia C, Poletti E, Crowson AN: Basosquamous carcinoma. J Am Acad Dermatol. 2009, 60:137-43. 10.1016/j.jaad.2008.09.036

13. Dixon AY, Lee SH, McGregor DH: Histologic features predictive of basal cell carcinoma recurrence: Results of a multivariate analysis. J Cutan Pathol. 1993, 20:137-42.

14. Hall WA, Stapleford LJ, Hadjipanayis CG, Curran WJ, Crocker I, Shu HK: Stereotactic body radiosurgery for spinal metastatic disease: An evidence-based review. Int J Surg Oncol. 2011, 2011:979214. 10.1155/2011/979214

15. Chang EL, Shiu AS, Mendel E, Mathews LA, Mahajan A, Allen PK, Weinberg JS, Brown BW, Wang XS, Woo SY, Cleeland C, Maor MH, Rhines LD: Phase I/II study of stereotactic body radiotherapy for spinal metastasis and its pattern of failure. J Neurosurg Spine. 2007, 7:151-60.

16. Sekulic A, Migden MR, Oro AE, Dirix L, Lewis KD, Hainsworth JD, Solomon JA, Yoo S, Arron ST, Friedlander PA, Marmur E, Rudin CM, Chang AL, Low JA, Mackey HM, Yauch RL, Graham RA, Reddy JC, Hauschild A: Efficacy and safety of vismodegib in advanced basal-cell carcinoma . NEJM. 2012, 366:2171-9. 10.1056/NEJMoa1113713

17. Chang AL, Oro AE: Initial assessment of tumor regrowth after vismodegib in advanced basal cell carcinoma . 


\section{Cureus}

Arch Dermatol. 2012, 148:1324-5. 10.1001/archdermatol.2012.2354

18. Zeng J, Aziz K, Chettiar ST, Aftab BT, Armour M, Gajula R, Gandhi N, Salih T, Herman JM, Wong J, Rudin CM, Tran PT, Hales RK: Hedgehog pathway inhibition radiosensitizes non-small cell lung cancers. Int J Radiat Oncol Biol Phys. 2013, 86:143-9. 10.1016/j.ijrobp.2012.10.014 